\title{
Design of Sewerage System in Kirulapone for Colombo Municipality
}

\author{
Shahina M Mysan and Ananda Ranasinghe
}

\begin{abstract}
The sewerage system in the Colombo city had been laid by the British a few centuries ago and whatever development that is presently being done is augmentation of the whole system. Frequently a few additions have also been made to the system but due to financial constraints these additions are being done at a very slow pace.
\end{abstract}

Discharging sewage is also important as collecting sewage. However, the method of discharging sewage to the ocean without any treatment whatsoever had been practised from the very inception and this has continued up to the present time. Although there had been environmental pollution from the beginning, due to the fact that the population and volume of sewage being extremely small at that time, the level of pollution had not been significant. However, with the enlarged population as well as increase in the volume of sewage over the years, there should be some form of sewage treatment before discharging same into the ocean.

However, as the authorities are finding it extremely difficult even to finance expansion needs, it is very unlikely that sewage will be treated in the near future before discharging into the ocean and this may pose a problem that may have to be faced by the authorities as well as environmentalists for a long time to come.

Key words: $\quad$ CMC, Sewerage, Environment, Sewer Network, Pollution

\section{Introduction}

Development goes hand in hand with the progress of civilisation and it is inextricably interwoven with each other. No proper positive development can be achieved with certainty without adequate and proper infrastructure. There are only a few towns in Sri Lanka where there is a well laid sewerage system. Although the British commenced the laying of a sewerage system in Colombo when they started settling in Colombo as their capital city, the same advancement of expanding the sewerage system had not taken place either in the Colombo city or the rest of the island. Even in cities like Kandy, which is the next big city, the sewerage system had been introduced at a much latter stage. Presently, still we are using this age old sewerage pipe system augmented with a few improvements in the Colombo city. It is important to mention that $80 \%$ of Colombo city has a sewerage system whereas for the rest of the areas planning has begun to lay sewerage pipes. The areas that are not covered presently are Mattakkuliya, Mahawatte, Bloemendhal, Narahenpita and Kirulapone.

There is no doubt that the old sewerage system has been designed for a population of less than $50 \%$ presently residing in Colombo. The improvement that has been done for the sewerage system is disproportionate to the increase in population. Therefore one could say that the present sewerage system is substantially overloaded and needs expansion and improvement. Sewerage systems, like the other

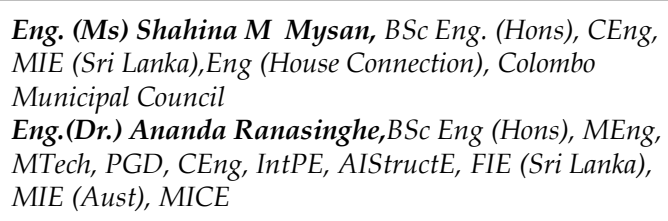

Eng. (Ms) Shahina M Mysan, BSc Eng. (Hons), CEng, MIE (Sri Lanka), Eng (House Connection), Colombo Municipal Council

Eng.(Dr.) Ananda Ranasinghe,BSc Eng (Hons), MEng, MTech, PGD, CEng, IntPE, AIStructE, FIE (Sri Lanka), MIE (Aust), MICE 
infrastructure, are very costly but unfortunately of these works are being done below the ground and therefore do not get much attention of the public. This may be one of the reasons that our investment in the sewerage system is comparatively little as it does not give much publicity to the politician.

A sewage system may convey wastewater by gravity to a sewage treatment plant. Where Pipeline excavation is difficult because of rock or there is limited topographic relief (i.e., due to flat terrain), gravity collection systems may not be practical and the sewage must be pumped through a pipeline to the treatment plant or pumping station. Pipelines range in size from pipes of six inches $(150 \mathrm{~mm})$ in diameter to man-entry tunnels. cannot handle the volume of runoff, resulting in combined sewer overflows and causing water pollution problems in nearby water bodies. Separate sanitary sewer systems are designed to transport sewage alone. In communities served by separate sanitary sewers, another pipe system is constructed to convey storm-water runoff directly to surface waters. Most municipal sewer systems constructed today are separate sewer systems. Although separate sewer systems are intended to transport only sewage, all sewer systems have some degree of inflow and infiltration of surface water and groundwater, which can lead to sanitary sewer overflows. Inflow and infiltration is highly affected by antecedent moisture conditions, which also represents an important design consideration in these systems.

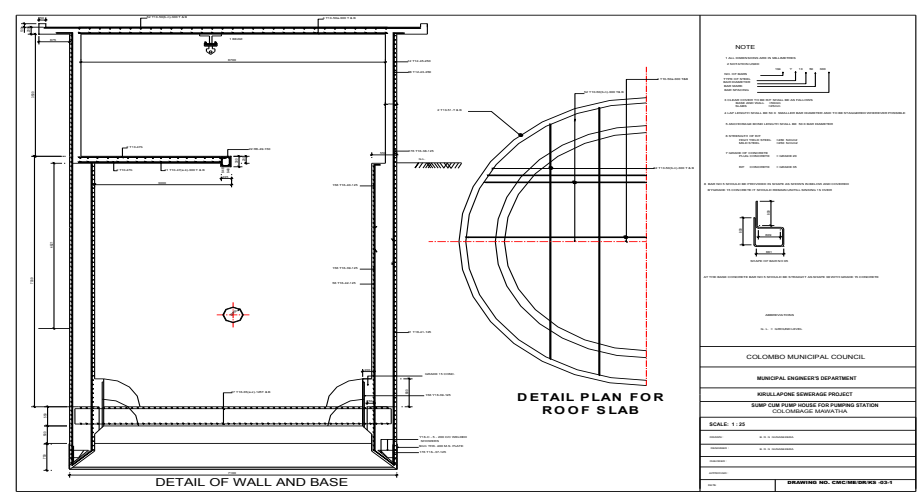

Figure 1 - Sump cum pump House - Reinforcement details

\section{Design and analysis of collection systems}

Design and sizing of sewage collection systems considers population served, commercial and industrial flows, flow peaking characteristics and wet weather flows. Combined sewer systems are designed to transport both storm-water runoff and sewage in the same pipe. Besides the projected sewage flow, the size and characteristics of the watershed are the overriding design considerations for combined sewers. Often, combined sewers

\section{Historical sewage conveyance and disposal}

The historical focus of sewage treatment was on conveyance of raw sewage to a natural body of water, e.g. a river or ocean, where it would be satisfactorily diluted and dissipated. Early human habitations were often built next to water sources. Rivers could double as a crude form of natural sewage disposal.

The Colombo sewerage scheme was initiated by the Government of Ceylon in 1896 when Mr. James Masergh past-president, Inst. C.E, was 
called in to advise. He tabulated the vital topographical and other statistics along with the first contour map of the city, and recommended a complete sewerage scheme upon the separate system with outfall works. Which the present scheme has been constructed. The Municipal Council at first raised objections to any system of underground sewers, but in 1901, with some encouragement by the Government the council consented to the commencement of the first installment.

Not until May 1906, that the necessary land - purchase was accomplished for work to be started on the main sewer and treatment work.

Constructional works with minor sewers in the Fort and Pettah wards were commenced on the first of June 1904.

Northern pumping station and primary treatment works were designed to deal with the sewerage from the whole city, but subsequent enlargements of the city boundaries necessitated the southern outfall.

No works of similar character had been previously attempted in Ceylon before. The labour force had to be trained in the timbering of trenches and the methods required for dealing with ground water.

This installment of the scheme was handed over to the Municipality for operation in September 1910. It dealt with a net habitable area of about 60 Acres with an estimated future population of about 60,000 . The cost of the works, including land - acquisition estimated to Rs. 4,848,888.00.

In November, 1911, the boundaries of the Municipality were extended eastward and Southward. A Sourthen Outfall was suggested with a pumping station.

Owing to the slow progress of the house connections, further detailed drainage proposals were postponed and public latrines and most of large institutions, hotels and offices were being connected.

The drainage division of Colombo Municipal Council records show that first drainage connection was given in
September 1910 to premises No.50/13, Prince Street.

\section{Industrial Revolution era}

As an outgrowth of the Industrial Revolution, many cities in Europe and North America grew in the 19th century, frequently leading to crowding and increasing concerns about public health. As part of a trend of municipal sanitation programs in the late 19th and 20th centuries, many cities constructed extensive sewer systems to help control outbreaks of disease. Initially these systems discharged sewage directly to surface waters without treatment. The first comprehensive sewer system was built in Hamburg, Germany in the mid-19th century.

Although the perception of the general public is that the ocean can absorb anything and everything, it is not so. This was revealed at the unfortunate tsunami disaster which affected the Sri Lankan coastal belt. One of the major problems that had to be dealt with after the tsunami was cleaning of the shores due to the floating debris from the sea. Therefore the ocean cannot absorb whatever garbage that is disposed into it. In Sri Lanka we do spend very little on the improvement of our infrastructure. Comparatively, most of the developed countries have a fair share in their budget for the improvement of their infrastructure. These improvements in the developing countries are also carried out in a systematic manner so that minimal harm would be done to the environment. Environmental pollution has become a serious issue in the developed countries and it has now expanded to the developed countries as well. Although countries like India have mass scale factories contributing to development and production, they are also responsible for similar scale pollution as most of the effluents are being discharged into rivers and streams without proper treatment. Therefore, the treatment of sewerage is also equally important as establishing a sewerage infrastructure. However, in countries like Sri Lanka, the mere maintenance of the present sewerage system and adding the necessary extension is beyond the capacity of some of the organizations who are responsible for 
providing such services. Therefore they show very little consideration for the treatment of sewage as it is going to be impossible due to the cost involved.

In the present sewerage system covering Colombo there are two major sea outfalls one at Wellawatte and the other at Madampitiya. At these outfalls sewage is taken into the sea up to a distance of approximately $1.5 \mathrm{Km}$. before discharging. However, even preliminary treatment is not being done purely due to the cost factor. Presently, Dehiwela/Mount Lavinia and Kolonnawa Municipal Councils connect their sewer outlets to the Colombo sewerage system whereby the Colombo sewerage system is further overloaded due to this fact.

In the Colombo sewerage system there are frequent blocks and collapses as the majority of it had been made quite some time back. Repairing of these collapses and blocks themselves is a major project due to the dilapidated condition of the sewerage system. Although after laying or maintenance of a sewerage system, testing has to be done in order to ensure its water tightness which is not being done presently in a systematic manner. Therefore there is a possibility that there is a lack of water tightness and as a result the raw sewage could contaminate streams, rivers and other water estuaries such as ground water.

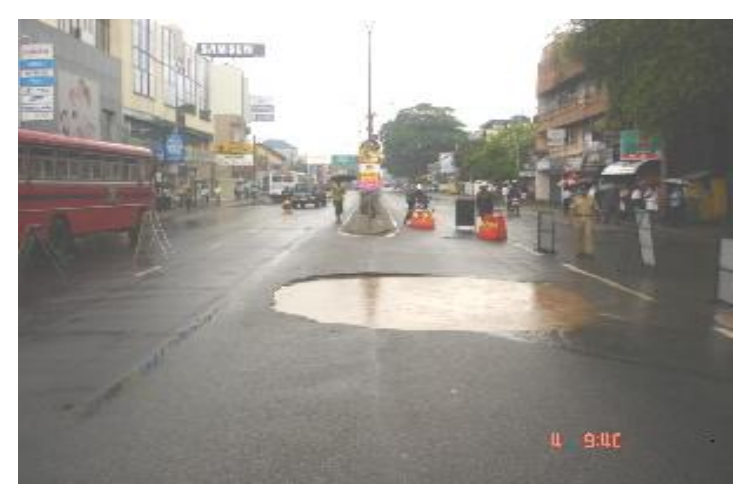

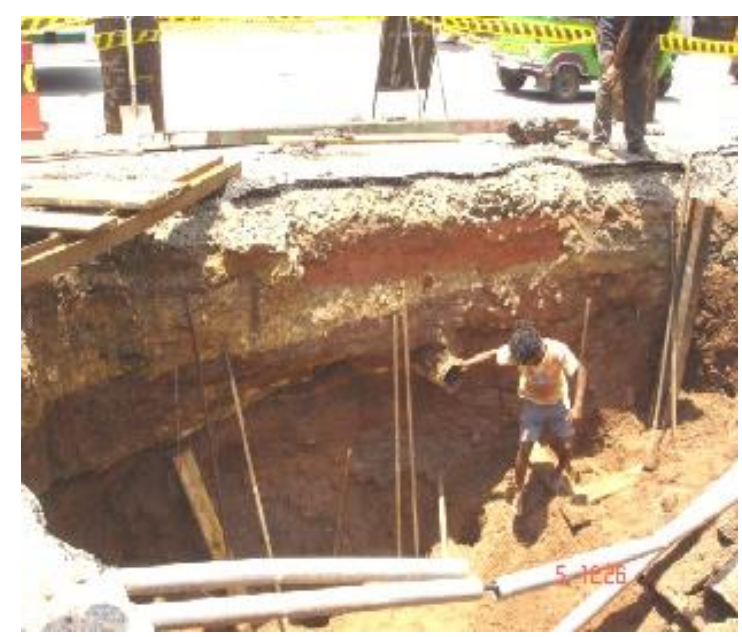

Figure 2 \& 3 - Recent sewer collapse at Wellawatte

In order to augment the sewerage system, recently the pump house at Madampitiya has been expanded. Furthermore, construction is in progress for two more pump stations at Mattakkuliya and Wanathamulla. In order to support the present expansion in population in the Kirulapone area a new pump station at Swarna Road has been proposed and already the design work is completed. However, the construction of the pump station has not yet commenced but connected sewerage network is under construction.

A further pump station has been designed at Kalinga Mawatha in order to cater to a population of 25,000. This pump station is bounded by Elvitigala Mawatha on one side and the canal near the Open University and Vijaya Kumaratunga Mawatha on the other side. The catchment area for this pump station is approximately 65 hectares and this project consists of a $3.75 \mathrm{Km}$ long gravity sewer network and a pump having $775 \mathrm{~m}$ force main.

The design of this pump station and the gravity network has been done by a co-author of this paper. The gravity line which is part of the development project and the pump main is shown in the attached map. The project comprises a $33 \mathrm{~m}^{3}$ capacity sump with the piping system of diameter varying from $150 \mathrm{~mm}$ to $300 \mathrm{~mm}$. The design of the sump was done according to the BS 8110 and 8007. The designer has also used 
Reinforced Concrete Design Handbook by Reynolds and Steadman and other references listed in the paper. The concrete grade 35 had been used for the sump and for the purpose of laying pipelines grade 20 was used.

The major factor determining the pump capacity was the number of working hours of the pump. Due to various restrictions such as working hours, maintenance, capacity etc. it was assumed that the pumps are working for a duration of 12 hours per a day.

For the purpose of calculating the inflow of wastewater an assumption was made that the inflow of wastewater was uniform and proportionate to the population. It was assumed that from Elvigatigala Mawatha to Kalinga Mawatha along Vijaya Kumaratunga Mawatha, the total number of houses are 450 at an average of 5 persons per house. Based on this information and a growth rate of $1 \%$, the anticipated population for 25 years was calculated as the designed life of the sump was assumed as 25 years. Similarly discharge from the other areas coming within the catchment area was taken into account in order to arrive at a total population anticipated for 25 years.

\section{Designing of Gravity Pipe Network}

The principles adopted in the design of gravity mains and the sump are different to each other. In a gravity main one has to consider the peak flow of the catchment area as it would adversely affect the overloading of the piping system. In order to calculate the peak flow a factor of 4 was taken which is generally used in the design of this type of infrastructure. Due to the nature of the area as well as the other associated structures which connect the pipeline always there is a possibility of infiltration of water. It was assumed that a person consumed 200 litres per day with a reasonable loss of water of $10 \%$. So the actual consumption of water by a person is approximately 180 litres per day. The infiltration of water has to be added to the water calculated from consumption in order to obtain the designed flow. It is also important to note that when designing wastewater pipes one would not design for the full flow condition as an allowance has to be made for the development of gaseous compound in the sewage. Therefore the designer has used half full flow capacity in order to size the pipes. It is also important to consider that the gaseous compound collected in the sewer has to be discharged and therefore vent shafts are provided at upper most locations as well as all the house inlet points. Typical vent shaft in the Colombo sewerage system is shown in the figure 6 .

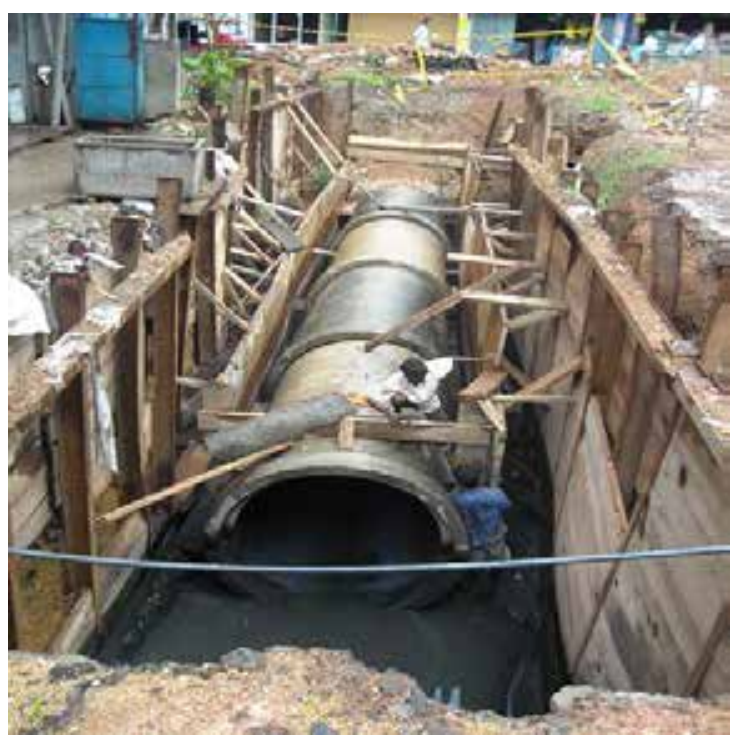

Figure 4 - Laying of Sewer Pipe Lines on a graded fill

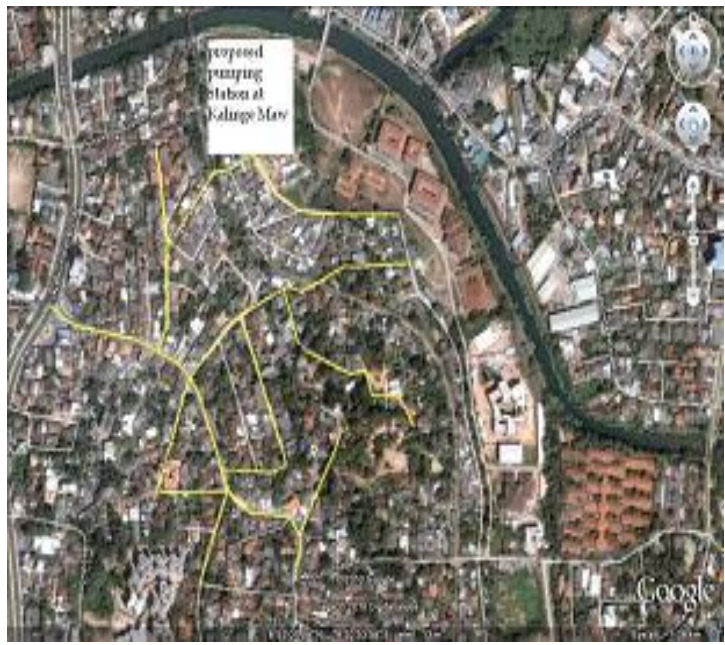

Figure 5 - Location Map 

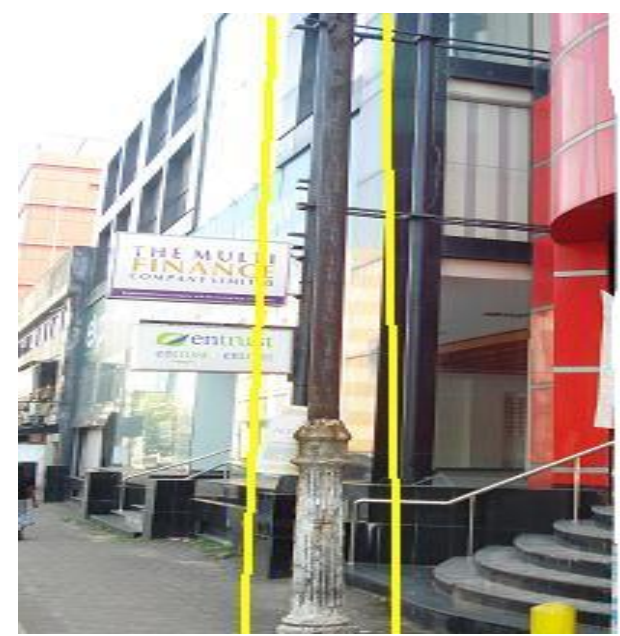

Figure 6 -Typical Vent shaft at Duplication Road

\section{Force Main}

Force mains are pipe lines that convey waste water under pressure from the discharge side of a pump to another discharge point, preferably another pumping station. Pumps located in a lift station provide the energy for waste water conveyance in force mains. The key elements in a force main system can be identified as Pipes, Valves, Pressure surge control devices and Force main cleaning system.

Force mains are used to convey wastewater from a lower to a higher elevation. In this Project the elevation of the source is not high enough for gravity flow. There were situations where use of gravity conveyance will result in excessive excavation depths and higher construction costs. Ductile iron, polyvinyl chloride or cast iron is the most frequently used material for wastewater force mains.

While construction of force mains system excluding the other accessories, is less expensive than gravity sewer lines for the same flow, force main wastewater conveyance requires the construction and operation of one or more lift stations. Force mains are very reliable when they are properly designed and maintained. In general, reliability and useful life of force mains are comparable to that of gravity sewer lines, but pipeline reliability may be compromised by excessive pressure surges, corrosion or lack of routine maintenance.

Use of force mains can significantly reduce the size and depth of sewer lines and decrease the overall costs of sewer system construction. Typically, when gravity sewers are installed in trenches deeper than $6.0 \mathrm{~m}$, the cost of sewer line installation increases significantly because more complex and costly excavation equipment and trench shoring techniques are required.

Force main installation is simple because of shallower pipe line trenches and reduced quantity of earth work. Installation of force mains is not dependent on site specific topographic conditions and is not impacted by available terrain slope, which typically limits gravity wastewater conveyance.

\section{Design Criteria}

The major factors considered in analyzing force main materials and hydraulics include the design formula for sizing the pipe, friction losses, pressure surges, and maintenance. The Hazen Williams formula and Cole Brook- White formula are recommended for the design of force mains. These formulae include a roughness coefficient, which accounts for pipeline hydraulic friction characteristics. The roughness coefficient varies with pipe material, size and age.

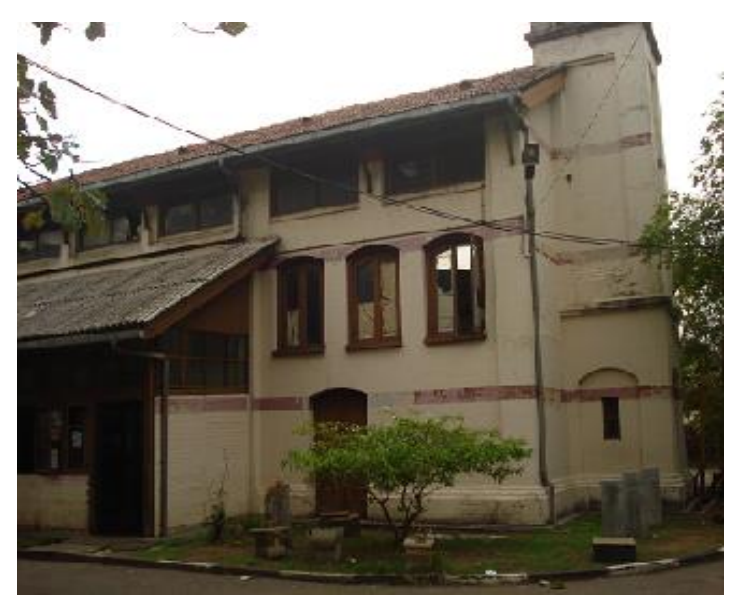

Figure 7 - One of the pumping station in Colombo 

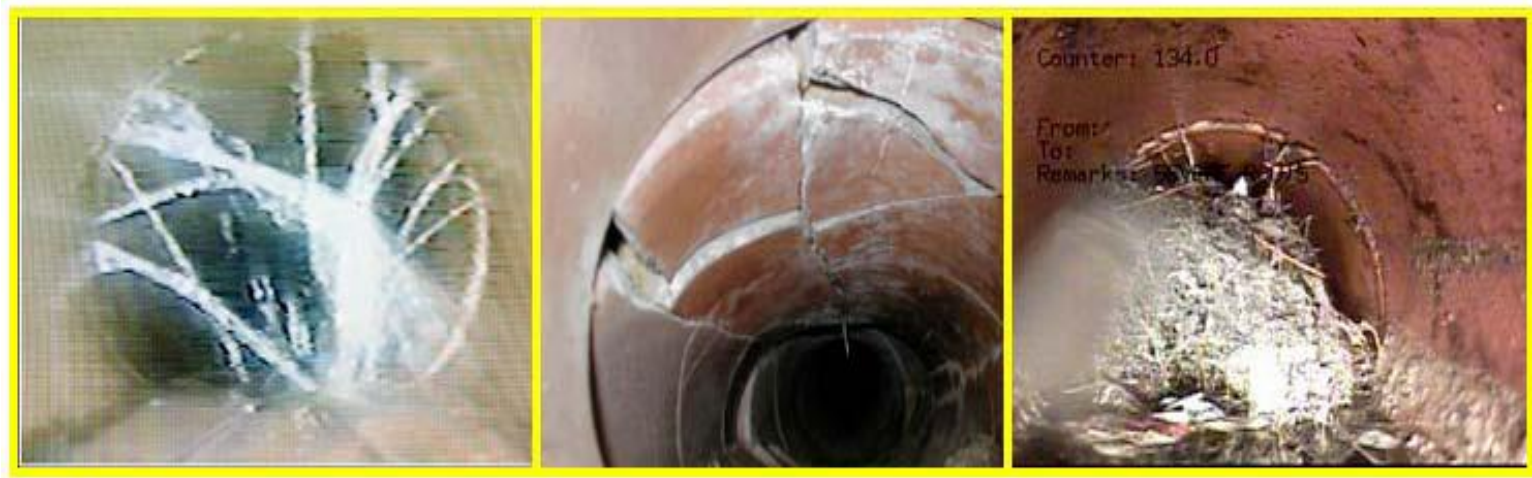

Figure 8-CCTV inspection shows Leaking Joints and Cracked pipes in a sewer

Force mains are typically designed for velocities between $0.75 \mathrm{~m} / \mathrm{s}$ (self cleansing velocity) to $3.0 \mathrm{~m} / \mathrm{s}$ (non scouring velocity). Such velocities are normally based on the most economical pipe diameters and typical available heads. For shorter force mains (less than 600 meters) and low lift requirements (less than 9 meters) the recommended force main velocity range is 1.8 to $2.7 \mathrm{~m} / \mathrm{s}$. This higher design velocity allows the use of smaller pipe, reducing construction costs. Higher velocity also increases pipeline friction loss by more than $50 \%$, resulting in increased energy costs.

Valves are installed to regulate wastewater and pressure in the force mains. Valves can be used to stop and start flow, control the flow rate, divert the flow, prevent backflow, and control and relieve the pressure. Air valves are provided at higher elevations while scour valves are provided at lower elevations. Force main performance is closely tied to the performance of the pumping station to which it is connected. System head curves are used to define and compare the operating characteristics of a given pump or set of pumps with the associated force main. They are also used to identify the best combination of performance characteristics under which the pumping station - force main system will operate under typical conditions.

The operation of force main - pumping station systems is usually automated and does not require continuous on-site operator presence.
However annual force main route inspections are recommended to ensure normal functioning and to identify potential problems. Except the forcemain rest of the lines in the system operate on gravity. Generally the pump house is located at the lower most point system so as in this case as well. From this point sewage is pumped out from the force- main. In order to calculate the capacity of pump one has to work out the losses in the system. Losses are developed in the system due to the presence of air valves, scour valves, bends and fiction losses in the pipe system etc. The formula used for calculating the losses is Darcy Weisbach equation. It is evident from the equation that the loss in the system is proportionate to the square of velocity of flow. It is also important to mention that due to this high velocity in the force-main the type of flow taking in the piping system is turbulent flow.

In order to calculate the total system head the losses due to fiction of the pipe and losses due to bends and valves were calculated. The system head was calculated as static head plus frictional losses. Thereafter, this total head plotted against the quantity of discharge in order to select the required pump. Performance of the Pump curves are generally available with the manufacturers of the pumps. In order to have a reliable source of pumping always in sewer system a standby pump is used.

Generally Centrifugal pumps are widely used for pumping sewerage due to the fact that they can be installed with minimum difficulty and at the same time they have an advantage that no clogging of sewer is taken place. In this Project it was assumed that the pump efficiency is $75 \%$. These pumps are submersible pumps which 
operate automatically when the sewer collected reaches a certain level. In order to calculate the capacity of sump 12 hours storage was assumed.

Well sinking method was proposed to adopt in the construction process. Therefore it was decided to use cylindrical sump for this Project. The sump was designed using shell analysis as well as service and ultimate load conditions were used in order to design reinforcement for this reinforced concrete structure. As this was designed as a water retaining structure in order to prevent pollution of the environment. British standard 8007 was used in design of the structure.

\section{Conclusion}

In the city of Colombo before the introduction of the sewerage system, liquid sewage had been stagnated in the surface drains and until it was washed away by rain into the soil through the canals, swamps and lakes. The solid sewage had been collected at night by night-soil carts and had been buried in the vicinity. With the expansion of the population and the primitive and unhygienic methods of disposing soil had become unfeasible and unworkable. Furthermore spreading diseases might have become a major threat. Higher population densities requires more complex sewer collection and conveyance systems to maintain sanitary conditions in crowded cities. It has been reported that in the year 1910 the cost of the sewage system in Colombo has been estimated as Rupees $4,848,000 /$-. This indicates that cost of the sewage system more than $100 \mathrm{~m}$ years back. Given the damage that untreated sewage can pose to the environment, and the cost of running sewage lines to rural areas, onsite treatment and disposal is a cost effective, practical, and sometimes beneficial way of dealing with sewage.
Pollution in the ocean is a major problem that is affecting the ocean and the rest of the Earth, too. Pollution in the ocean directly affects ocean organisms and indirectly affects human health and resources. Oil spills, toxic wastes, and dumping of other harmful materials are all major sources of pollution in the ocean.

However with the uncontrolled development the wastage and the contribution from the sewerage is so enormous it has now reached unprecedented levels which is not manageable. Therefore as citizens one has to be conscious with respect to the difficulty in providing suitable infrastructure for this unmanageable and insurmountable problem and support the effort taken by the authorities to tackle this difficult and arduous dilemma with limited recourses.

\section{References}

1. BS 8110 : Structural use of concrete Part 1, (1997) Code of practice for design and Construction. British Standard Institute. U.K.

2. BS 8007 : Design of Concrete Structures for retaining aqueous liquid, (1987) British Standard Institute. U.K.

3. Portland Cement Association (1981) Tables 1-7.

4. Reinforced Concrete Designers Handbook, Reynolds \& Steadman $10^{\text {th }}$ Edition.

5. Robert Thomas "paper from ICI of proceedings", vol 216; 1923. The Institution of Civil Engineers.

6. Dr. Jain, A. K., “Fluid Mechanics. Khanna Publishers Delhi.

7. Small Sewage Treatment Works, British Standard Institution

8. Sewage Disposal and Air Pollution Engineering - Vol. II, S. K. Garg

9. Professional Examination Design Report, Shahina M. Mysan 